\title{
Is it time for a CT scanner in every Canadian rural hospital?
}

\author{
Richard Fleet $^{1,2,3} \cdot$ Philippe Brochu $^{1} \cdot$ Pierre-Gilles Blanchard ${ }^{1,2}(\mathbb{D}$
}

Received: 2 August 2021 / Accepted: 6 August 2021

(C) The Author(s), under exclusive licence to Canadian Association of Emergency Physicians (CAEP)/ Association Canadienne de Médecine d'Urgence (ACMU) 2021

"Please stand if the answer to any of the following questions is yes", Dr Fleet asked the room filled with ED physicians at a major conference. "Do you currently live in a rural area? Do you have loved ones who live there? Do you work in a rural area? Do you travel to rural areas to practice your favorite outdoor sport?" By the time he asked who takes transfers from rural areas, he had the full room standing, attendees looking puzzled. "Where is he going with this?" they probably thought. Rural EDs are safety nets not only for the $20 \%$ of Canadians who live there, but also for health care providers and their loved ones. For the past decade, Dr Fleet's research group has studied one aspect or another of rural emergency care in more than 300 rural hospitals in Canada, defined as institutions located in cities with a population of less than 15,000, 24/7 physician coverage, patient admission capability, and located more than $50 \mathrm{~min}$ of ground transport from a level 1 or 2 trauma centre. They found that rural EDs in Canada treat more than 3 million patients per year. Except in the Province of Quebec, less than $20 \%$ of rural EDs in Canada have a CT scanner, surgery capabilities, and a critical care unit. Half of rural EDs are more than $300 \mathrm{~km}$ from an urban referral centre. As a probable consequence of the limited access to services, trauma mortality in rural areas is three times higher than in urban areas and the 30-day in-hospital mortality following stroke is $25 \%$ higher $[1,2]$. Those findings brought the conference room to a dead silence.

As we are writing these lines today, in reflection of the study by Watchorn et al. published in this edition, we ask

Pierre-Gilles Blanchard

Pierre-gilles.blanchard.1@ulaval.ca

1 Department of Family and Emergency Medicine, Laval University, Québec, QC, Canada

2 VITAM - Centre de recherche en santé durable de l'Université Laval, Québec, QC, Canada

3 Research Chair in Innovation and Emergency Medicine, Laval University-Dessercom-CISSS Chaudière-Appalaches, Lévis, QC, Canada you to pay attention to their findings and support your ED colleagues in the fight to tackle rural health care inequities [3]. Let us put a CT scanner in most rural EDs. Unnecessary transfers, delayed diagnoses, and delayed treatments for time-critical conditions must stop.

We spoke with Dr Watchorn for this editorial. His paper was not written for the advancement of his academic career-most of these careers are still in urban centres. It was written for one specific purpose: convince the decisionmakers of his community's need for a CT scanner. Having witnessed the numbers of transfers for a CT scan, the delays for emergent scans and the long-term consequences of delays in timely diagnosis for conditions such as stroke and other surgical emergencies, they asked for a CT scanner and were turned down because of low patient volumes.

So, they conducted this study, just like Dr Fleet did in Nelson, BC in 2010, and several years thereafter in BaieSaint-Paul, Québec [4]. But they did it better. They gathered prospective transfer data for one full year. And, because no electronic database existed, they had to manually extract information from patient charts and CT reports. In this rural ED in Golden, BC with roughly 9000 visits annually, over 200 patients needed to be transferred. $60 \%$ of all transfers received a CT scanner. Time from CT request to $\mathrm{CT}$ scan at the receiving hospital was $6 \mathrm{~h} 52$ for emergent requests and $4 \mathrm{~h} 44$ for stroke. According to the study, $38 \%$ of the transfers could have been avoided with a local CT scanner. A total of $92 \%$ of patients were transported by road ambulance, for at least $250 \mathrm{~km}$ - the distance to the closest CT scanner!

Inter-facility transfers are a major issue for rural stakeholders. The Rural Road Map Implementation Committee (RRMIC), a committee lead by the College of Family Physicians of Canada and the Society of Rural Physicians of Canada, worked for the past several years on identifying problems and solutions to improve rural health care. As the issue of transfers was seen as a priority, it dedicated a specific task force that uncovered that there is no easily accessible database on rural-urban interfacility transfers in Canada. Even the Canadian Institute for Health Information 
(CIHI), at the time of writing this, admitted to not having such data. We need to get to this information on a national basis now. Meanwhile, the RRMIC calls on leaders to evaluate, improve, and reduce the need for patient transfers and to support investments in appropriate diagnostic imaging in rural settings.

If you cannot get an emergent CT scan to diagnose timecritical conditions, if you need to transfer a significant portion of patients over hundreds of $\mathrm{km}$ to get an exam or if you cannot comply with guidelines for treatment of common emergencies such as stroke, then, well, you probably need one. The cost of purchase and maintenance of a CT scanner will likely be offset by the benefits of having one. The latter include timely diagnoses of potentially life-threatening conditions, improved triage for transfers, reduction in avoidable transfer costs and double billing from an additional consultation in an already overcrowded referral center. Also, a rural ED with a CT scanner is more attractive for health care professionals: recruitment and retention is a critical issue identified by the RRMIC group. No one wants to start his career going to bed at night second guessing his or her clinical judgement because he decided to sit on a grey zone clinical condition that an otherwise available CT scanner could have clarified in minutes. Moreover, it can be argued that in 2021, a CT scanner is a standard of care in the practice of emergency medicine, not some kind of overpriced luxury. Not addressing delays such as those measured by Dr Watchorn in rural EDs perpetuates inequitable access to care for people living in rural and remote communities.

If you are still not convinced of the necessity of a CT scanner in a rural ED solely based on volume metrics then we encourage you to replicate Watchorn et al.'s study, add a cost analysis, conduct a qualitative study interviewing patients that were transferred, receiving centres, paramedics, and so on. But before you embark on such a journey, remember this study that demonstrated how the installation of the first rural CT scanner in Canada changed the area's health care in significant ways...15 years ago [5]! We, however, will not wait that long to advocate for a CT scanner in most rural hospitals.

\section{Declarations}

Conflict of interest The authors declare that they have no conflict of interest.

\section{References}

1. Fleet R, Lauzier F, Tounkara FK, Turcotte S, Poitras J, Morris $\mathrm{J}$, et al. Profile of trauma mortality and trauma care resources at rural emergency departments and urban trauma centres in Quebec: a population-based, retrospective cohort study. BMJ Open. 2019;9(6):e028512.

2. Fleet R, Bussières $\mathrm{S}$, Tounkara FK, Turcotte $\mathrm{S}$, Légaré F, Plant J, et al. Rural versus urban academic hospital mortality following stroke in Canada. PLoS One. 2018;13(1):e0191151.

3. Watchorn A, Curran J, Evans Z, Wong V. Evaluating delays for emergent CT scans from a rural British Columbia hospital. CJEM. 2021. https://doi.org/10.1007/s43678-021-00147-2.

4. Fleet R, Plant J, Ness R, Moola S. Patient advocacy by rural emergency physicians after major service cuts: the case of Nelson, BC. Can J Rural Medicine Official J Soc Rural Physicians Can J Can De La Médecine Rurale Le J Officiel De La Société De Médecine Rurale Du Can. 2013;18(2):56-61.

5. Merkens BJ, Mowbray RD, Creeden L, Engels PT, Rothwell DM, Chan BTB, et al. A rural CT scanner: evaluating the effect on local health care. Can Assoc Radiologists J J L'association Can Des Radiologistes. 2006;57(4):224-31. 